\title{
КАЧЕСТВО СИСТЕМЫ УПРАВЛЕНИЯ ГОССЕКТОРОМ НИОКР И ИННОВАЦИЙ: ПОПЫТКИ КОЛИЧЕСТВЕННОГО АНАЛИЗА
}

\author{
(c) 2019 Лебедев Константин Николаевич \\ доктор экономических наук, доцент, профессор Департамента экономической теории \\ Финансовый университет при Правительстве Российской Федерации, Россия, Москва \\ E-mail:KNLebedev@fa.ru \\ (c) 2019 Лачкова Виктория Константиновна \\ аспирант Департамента экономической теории \\ Финансовый университет при Правительстве Российской Федерации, Россия, Москва \\ E-mail:vikalachkova@yandex.ru
}

Отсутствие у страны заметных успехов в инновационном развитии побуждает искать новые подходы к оценке и проектированию институциональных реформ в российском секторе знаний. Одним из таких подходов является количественный анализ соотношений альтернативных способов исполнения функций социальных взаимодействий в области организации производства и управления, а также организационной культуры. В данной статье этот подход применяется не только для оценки состояния организации управления сектором НИОКР и инноваций, контролируемым государством, но и для оценки масштабов самого этого сектора.

Ключевые слова: НИОКР, инновации, государственный сектор знаний, властная вертикаль, централизованная тематика, назначаемость руководителей.

Очевидно, что российское государство, задавшись целью перевода страны на инновационный путь развития, делает ставку в развитии НИОКР и инноваций в стране на прямое участие в этой деятельности организаций, контролируемых государством, и на соответствующие госзакупки (прямое государственное финансирование НИОКР и инноваций). В 1-м случае государство стремиться заставить организации заниматься НИОКР и инновациями, пользуясь их подконтрольностью, во 2-м - на основе соответствующего госзаказа, причем зачастую оба способа побуждения к НИОКР и инновациям используются государством одновременно, например, когда соответствующий заказ исполняет организация, контролируемая государством. Пример использования 1-го способа - побуждение крупнейших госкомпаний принять и реализовывать с 2011 г. программы инновационного развития (ПИР), состоящие из программ НИОКР и инноваций, по инициативе Президента РФ $[1$, c. 10], 2-го - введение госзадания в области научно-технической деятельности, заработавшего с 2015 г.

Подтверждением сказанному в начале предыдущего абзаца являются данные о динамике долей собственности, контролируемой государством, во внутренних затратах на НИОКР (или

внутренних затратах на исследования и разработки - ВЗИР) и затратах на инновации и долей источников их финансирования, контролируемых государством, во ВЗИР и затратах на инновации.

В таблице 1 представлены данные о долях собственности, контролируемой государством, во ВЗИР и затратах на инновации.

В таблице 2 представлены данные о долях источников финансирования, контролируемых государством, во ВЗИР и затратах на инновации.

Таблица 1 показывает, что, начиная с 2000 г., российское государство постоянно расширяло контроль над собственностью, занятой во ВЗИР, и какая-то стабилизация доли собственности, контролируемой государством, во ВЗИР, наступила в 2017 г. Она также показывает, что, начиная с 2011 г., российское государство резко расширило контроль над собственностью, занятой в инновациях, хотя с 2015 г. начиналось его определенное ослабление. Таблица 2 показывает, что, начиная с 2011 г. российское государство усиливало контроль над источниками финансирования ВЗИР и затрат на инновации, хотя в 2016 г. наступили его стабилизация в части источников финансирования ВЗИР и некоторое ослабление в части источников финансирования инноваций. Тем не менее, представленные цифры по- 
Таблица 1. Доли собственности, контролируемой государством, во ВЗИР и затратах на инновации в 2000-2017 гг.,\%

\begin{tabular}{|l|c|c|c|c|c|c|c|c|c|c|}
\hline $\begin{array}{l}\text { Доля собственности, подконтрольной } \\
\text { государству }\end{array}$ & 2000 & 2005 & 2010 & 2011 & 2012 & 2013 & 2014 & 2015 & 2016 & 2017 \\
\hline 1. Во ВЗИР & 64,7 & 65,7 & 68,9 & 68,5 & 79,7 & 82,6 & 84,4 & 87,4 & 89,7 & 89,9 \\
\hline 2. В затратах на инновации & н/д & н/д & н/д & 55,2 & 61,6 & 89,9 & 93,0 & 89,6 & 80,0 & 76,3 \\
\hline
\end{tabular}

Источник: составлено авторами.

Примечание - Доля собственности, контролируемой государством, во ВЗИР была определена на основе публикуемых НИУ ВШЭ данных о долях во ВЗИР государственного и предпринимательского секторов науки, сектора высшего образования (сектор некоммерческих организаций - благотворительные организации, союзы, ассоциации и т.д.- точнее, его собственность, государству неподконтролен). При этом госсектор (НИИ, подведомственные ФОИВ и другим госорганам) полностью контролируется государством, а предпринимательский сектор (НИИ, принадлежащие производственным компаниям, сами эти компании, если они осуществляют ВЗИР, частные коммерческие НИИ и т.д.) и сектор высшего образования контролируются государством частично. Доля предпринимательского сектора, контролируемого государством, была определена по доле затрат на НИОКР, осуществленных по ПИР госкомпаний, в общей величине ВЗИР предпринимательского сектора, а таковая сектора высшего образования - по доле государственных вузов в общей численности студентов российских вузов.

Доля собственности, контролируемой государством, в затратах на инновации, была определена на основе сведений о затратах на инновации и затратах на инновации в НИР, публикуемых НИУ ВШЭ, данных о затратах на инновации госкомпаний в рамках ПИР и о доле секторов, контролируемых государством, во ВЗИР, кроме предпринимательского сектора. На основе последнего показателя была определена величина затрат на инновации в НИР секторов, контролируемых государством, кроме предпринимательского сектора, т.е. на госсекторов науки и высшего образования, имея в виду, что затраты на инновации в НИР предпринимательского сектора, контролируемого государством, уже учтены в затратах на инновации госкомпаний по ПИР.

Таблица 2. Доли источников финансирования, контролируемых государством, во ВЗИР и затратах на инновации 2011-2016 гг.,\%

\begin{tabular}{|l|c|c|c|c|c|c|c|}
\hline $\begin{array}{c}\text { Доли источников финансирования, } \\
\text { контролируемые государством }\end{array}$ & 2011 & 2012 & 2013 & 2014 & 2015 & 2016 & 2017 \\
\hline 1. Во ВЗИР & 82,0 & 91,9 & 89,2 & 90,8 & 92,0 & 92,9 & 92,9 \\
\hline 2. В затратах на инновации & 48,7 & 58,6 & 68,8 & 72,0 & 75,7 & 71,3 & н/д \\
\hline
\end{tabular}

Источник: составлено авторами.

Примечание - Доля источников финансирования, контролируемых государством, во ВЗИР, была определена на основе публикуемых НИУ ВШЭ данных о долях во ВЗИР средств государства (средств государственного бюджета, ассигнований на содержание образовательных учреждений высшего образования, средств организаций государственного сектора науки), предпринимательского сектора, образовательных учреждений высшего образования (средства некоммерческих организаций и иностранных источников государству неподконтрольны). При этом средства государства полностью контролируются государством, а средства предпринимательского сектора и образовательных учреждений высшего образования контролируются им частично. Их контролируемые государством доли во ВЗИР были определены по долям соответствующих секторов, контролируемых государством, во ВЗИР.

Доля источников финансирования, контролируемых государством, в затратах на инновации, была определена на основе данных о затратах на технологические инновации (составляющих 99\% всех затрат на инновации) по основным видам деятельности и источникам финансирования, публикуемым НИУ ВШЭ, а именно о собственных средствах организаций, средствах бюджетов всех уровней (средства фондов поддержки науки и техники, иностранные инвестиции и прочие источники государству неподконтрольны). При этом собственные средства организаций подконтрольны государству лишь частично, а бюджетов всех уровней - полностью. Подконтрольная государству часть собственных средств организаций была определена на основе доли собственности, подконтрольной государству, в затратах на инновации.

казывают, что инновационное развитие российской экономики государство взяло на себя, т.е. делает ставку в нем на государственный сектор знаний. Это требует изучения вопроса, насколько эффективно организовано управление инновационным развитием страны в той его части, которая контролируется государством.

Адекватное управление подконтрольными государству организациями, осуществляющими НИОКР и инновации, возможно только через властную вертикаль, предполагающую прямую подчиненность субъектов управления этих организаций органам исполнительной власти, в частности федеральным (ФОИВ). Она характерна для организаций (НИИ и вузов) государственных секторов науки и высшего образования, полностью контролируемых государством. Ее не может быть в секторе некоммерческих организаций, неподконтрольном государству. В предпринимательском же секторе во властную вертикаль встроены только субъекты управления производственных ГУПов (государственных 
унитарных предприятий) и учрежденных ими в форме тех же ГУПов дочерних компаний, включая НИИ. Субъекты же управления госкомпаний, созданных в форме акционерных обществ, лишь часть акций которых находится в собственности государства (например, Газпрома, НК Роснефть), и даже акционерных обществ, 100\% акций которых находится в госсобственности, и государственных корпораций (госкорпораций), капитал которых полностью принадлежит государству, во властную вертикаль не встроены. Их высшими органами управления выступают собрания акционеров, советы директоров [2] и наблюдательные советы [3] соответственно.

Соответственно, во властную вертикаль не встроены НИИ, учредителями (собственниками) которых выступают производственные госкомпании (кроме ГУПов) или их дочерние производственные компании, а именно в этих НИИ работает большая часть российских исследователей.

В таблице 3 представлены данные о долях властной вертикали во ВЗИР и затратах на инновации. Из таблицы 3 хорошо видно, что доли властной вертикали во ВЗИР и затратах на инновации существенно ниже долей в них собственности, контролируемой государством, причем тенденция к росту первых сменилась стабилизацией в 2011 и 2015 г. соответственно и некоторым снижением доли властной вертикали в затратах на инновации в 2017 г. Если в 2017 г. доля собственности, контролируемой государством, во ВЗИР, составляла 89,9\%, то доля в них властной вертикали составила 39,3\%. Это значит, что только 44,4\% (39,9/89,9*100) ВЗИР, осуществлявшихся организациями, подконтрольными государству, управлялись органами исполнительной власти. Если в 2017 г. доля собственности, кон- тролируемой государством, в затратах на инновации составляла 76,3\%, то доля в них властной вертикали - только 15,7\%. Это значит, что только $20,6 \%(15,7 / 76,3 * 100)$ затрат на инновации, осуществлявшихся организациями, контролируемыми государством, управлялись органами исполнительной власти.

Таким образом, российское государство в значительной мере не использует для повышения управляемости с его стороны подконтрольных ему организаций, осуществляющих НИОКР и инноваций, такую возможность, как прямое подчинение их субъектов управления властной вертикали. В связи с этим можно рекомендовать такое подчинение для субъектов управления акционерных обществ, контролируемых государством, и госкорпораций, путем соответствующего изменения законодательства или путем превращения акционерных обществ со 100\% акций в собственности государства и госкорпораций в ГУПы, далее, национализацию принадлежащих госкомпаниям НИИ с передачей их в непосредственное подчинение ФОИВ.

Адекватное управление государством НИОКР и инновациями через подконтрольные ему источники их финансирования основывается на утверждении государством тематики НИОКР и инноваций их исполнителям. Утверждением тематики государством (центром) является поручение государственными органами исполнителям осуществления НИОКР и инноваций на темы, определенные государством или отобранные ими из тем, предлагаемых самими исполнителями (по конкурсу или без него). Наряду с централизованной тематикой существует децентрализованная тематика, когда организации-исполнители самостоятельно определяют тематику работ, а государство их

Таблица 3. Доли властной вертикали во ВЗИР и затратах на инновации в 2000-2017 гг.,\%

\begin{tabular}{|l|c|c|c|c|c|c|c|c|c|c|}
\hline \multicolumn{1}{|c|}{ Доли властной вертикали } & 2000 & 2005 & 2010 & 2011 & 2012 & 2013 & 2014 & 2015 & 2016 & 2017 \\
\hline 1. Во ВЗИР & 31,5 & 34,3 & 40,1 & 39,3 & 41,7 & 39,4 & 40,3 & 40,7 & 41,1 & 39,3 \\
\hline 2. В затратах на инновации & н/д & н/д & н/д & 9,7 & 13,9 & 15,4 & 17,5 & 17,2 & 17,0 & 15,7 \\
\hline
\end{tabular}

Источник: составлено авторами.

Примечание - Доля властной вертикали во ВЗИР была определена на основе данных о доле во ВЗИР государственного сектора науки, публикуемых НИУ ВШЭ, ранее определенной доле во ВЗИР государственного сектора высшего образования и доле ГУПов во ВЗИР. Последняя была определена по данным о долях во ВЗИР предпринимательского сектора и сектора некоммерческих организаций, публикуемым НИУ ВШЭ, и доле ГУПов в ВВП, созданном этими секторами, установленной на основе данных расчета доли госсектора в ВВП, осуществленного РАНХиГС.

Доля властной вертикали в затратах на инновации была установлена на основе данных о затратах на инновации, публикуемых НИУ ВШЭ, затратах на инновации в НИР секторов, подчиняющихся властной вертикали (кроме предпринимательского сектора), т.е. государственных секторов науки и высшего образования, затратах на инновации производственных ГУПов. Последние были определены по данным о затратах на инновации госкомпаний в рамках ПИР и доле ГУПов в ВВП, созданном госкомпаниями, установленной на основе данных расчета доли госсектора в ВВП, произведенного РАНХиГС. 
финансирует.

Из СССР в современную Россию перешла практика масштабного формирования тематики (гражданских) НИОКР, финансируемых из государственного бюджета, на децентрализованной основе, объемы которой могут быть оценены по доле сметного бюджетного финансирования в источниках финансирования исследовательских организации (НИИ и вузов). Так, в 2002 г. сметное финансирование в структуре источников доходов НИИ академий занимало 65,0\%, а НИИ министерств и ведомств - 59,6\% [4, с. 38]. Система децентрализованного установления тематики НИОКР чревата дублированием исследований, мелкотемьем и, главное, опасностью пройти мимо перспективных направлений исследований. Как известно, российская наука в начале XXI в. оказалась отстающей по многим направлениям исследований, составляющим мировой тренд НИОКР. В этих условиях российское руководство стало принимать целенаправленные меры по сокращению доли децентрализованной тематики в финансируемых им НИОКР.

Среди этих мер можно назвать увеличение доли в общем финансировании РАН средств, направляемых на финансирование программ НИОКР отделений РАН и Президиума РАН. Эти средства затем распределялись между НИИ РАН (затем ставшими НИИ ФАНО, а сейчас - Минобрнауки) по конкурсу, т.е. были финансированием централизованно утверждаемой тематики, так как отделения и Президиум РАН фактически играли роль органов государственного управления НИОКР. Доля этих средств возросла с $10 \%$ в 2003 г. до $20 \%$ в 2004 г. [4, с. 33-34].

Другой важнейшей мерой стала замена сметного финансирования бюджетной субсидией на финансовое обеспечение выполнения госзадания в сфере науки, которая распределяется на финансирование централизованной и децентрализованной тематики. К централизованной тематике относятся директивные НИОКР и проекты лабораторий, из которых последние отбираются государственными органами-учредителями исследовательских организаций, по конкурсу. К децентрализованной тематике относятся проекты развития, отбираемые по конкурсу самими исследовательскими организациями, проекты ведущих ученых, несмотря на то, что сами ведущие ученые для целей господдержки отбираются по конкурсу госорганами-учредителями, ресурсное обе- спечение. В 2017 г. доля централизованной тематики в соответствующих субсидиях, полученных учреждениями высшего образования, подведомственными Минобрнауки, составила 50\% (в том числе доля директивной тематики 10 , проектов лабораторий - 40 [5]), а децентрализованной - также 50\% (в том числе доли проектов развития -25 , обеспечения деятельности лучших исследователей -15 , ресурсного обеспечения -10 [5]).

Несмотря на существенное увеличение доли централизованной тематики в НИОКР, финансируемых за счет бюджета, российское государство как будет показано ниже, далеко не полностью использовало соответствующую возможность увеличения управляемости с его стороны осуществляемых в стране НИКОР и инноваций.

Ситуация с централизованным утверждением тематики инноваций значительно хуже, прежде всего потому, что доля бюджетных средств в источниках финансировании затрат на инновации значительно меньше, чем в источниках финансирования ВЗИР. Так, в 2016 г. затраты на инновации составили 1284,6 млрд. руб., тогда как израсходованные на их финансирование средства федерального составили 392,9 млрд. руб.,, а региональных и местных - 3,2 млрд. руб. [6], всего - 396,1 млрд. руб. Таким образом, доля средств бюджета в затратах на инновации составила в 2016 г. 30,8\% (396,1/1284,6*100). В этом же году доля средств бюджета во ВЗИР составила $55,4 \%[7]$.

Кроме того, российское государство не разрабатывает и не утверждает программы инновационного развития (ПИР) госкомпаний, несущих основную нагрузку по инновационному развитию, в том числе планы инноваций, т.е. не утверждает тематику инноваций при расходовании такого контролируемого государством источника их финансирования, как собственные средства госкорпораций. Интересно, что государство (ФОИВ и т.д.) не утверждает ПИР не только тех госкомпаний, акции (капитал) которых принадлежит ему лишь частично, но и тех госкомпаний, капитал которых находится в полной собственности российского государства, а именно производственных ГУПов, госкорпораций и акционерных обществ со $100 \%$ акций в собственности государства. Так ПИР ФГУП «ГКНПЦ им. М.В. Хруничева» на 2011-2015 гг. был утвержден генеральным директором ФГУП «ГКНПЦ им. М.В. Хруничева» [8]. ПИР госкорпо- 
рации «Ростехнологии» на период 2011-2020 гг. был утвержден ее Наблюдательным советом [9]. ПИР акционерного общества АО «Системный оператор Единой энергетической системы» на 2016-2020 гг. и на перспективу до 2025 г. был утвержден решением Совета директоров акционерного общества [10].

Федеральный центр, естественно, не утверждает и отчетов об исполнении ПИР госкомпаний. Очевидно, что мониторинг разработки и исполнения ПИР госкомпаниями, которым занимается Межведомственная комиссия по технологическому развитию президиума президентского Совета по модернизации экономики и инновационному развитию, а также экспертиза ПИР госкомпаний, к которой привлекаются ФОИВ (на предмет соответствия отраслевой научно-технологической политике Минздрав, Минэнерго, Минпромторг, Минтранс и т.д., на предмет сотрудничества с НИИ и вузами - Минэкономиразвития, и пр.) [1, с. 13], далеко не равнозначна участию федерального центра в разработке тематики инноваций (а также НИОКР) и утверждению ПИР, означающему на порядок иной уровень ответственности ФОИВ за их тематику.

О ситуации с утверждением тематики российских НИОКР и инноваций государством говорят данные о долях централизованной тематики НИОКР и инноваций во ВЗИР и затратах на инновации. Данные, представленные в таблице 4 , характеризуют ситуацию в отношении ВЗИР с 2015 г., когда российское государство резко увеличило долю централизованной тематики
НИОКР, а затрат на инновации - с 2011 г., когда крупнейшие госкомпании обязали принимать и реализовывать ПИР.

Из таблицы 4 следует, что доля централизованной тематики во ВЗИР существенно ниже, чем доля в них источников финансирования, контролируемых государством. Если в 2017 г. доля централизованной тематики во ВЗИР составляла $62,0 \%$, то доля в них источников финансирования, контролируемых государством - 92,9\%, т.е. лишь 66,8\% (62,1/92,9*100) контролируемых государством средств в 2017 г. расходовались на НИОКР по тематике, утвержденной государством. При этом доля централизованной тематики демонстрируют тенденцию к снижению. Доля централизованной тематики в затратах на инновации также была существенно ниже доли в них источников финансирования, контролируемых государством, хотя у первого показателя наблюдается стабильный рост. Если в 2016 г. доля централизованной тематики в затратах на инновации составляла $36,8 \%$, то доля источников финансирования, контролируемых государством $-71,3 \%$, т.е. лишь $51,6 \%$ (36,8/71,3*100) контролируемых государством средств расходовались на инновации по тематике, утвержденной государством.

Таким образом, российское государство в значительной мере не использует для повышения управляемости с его стороны российских НИОКР и инноваций такую возможность, дающуюся ему подконтрольностью источников их финансирования, как утверждение их тематики. Для повышения доли централизованной

Таблица 4. Доли централизованной тематики во ВЗИР и затратах на инновации в 2011-2017 гг.,\%

\begin{tabular}{|l|c|c|c|c|c|c|c|}
\hline \multicolumn{1}{|c|}{ Доли централизованной тематики } & 2011 & 2012 & 2013 & 2014 & 2015 & 2016 & 2017 \\
\hline 1. Во ВЗИР & н/д & н/д & н/д & н/д & 66,7 & 64,0 & 62,0 \\
\hline 2. В затратах на инновации & 14,4 & 26,9 & 26,0 & 29,2 & 34,4 & 36,8 & н/д \\
\hline
\end{tabular}

Источник: составлено авторами.

Примечание - Доля централизованной тематики во ВЗИР была определена на основе публикуемых Минобрнауки данных о структуре ВЗИР по источникам финансирования, исходя из того, что централизованная тематика представления только в расходах бюджета и расходах секторов науки (государственного и предпринимательского, секторов высшего образования и некоммерческих организаций). Ее нет в долях собственных средств организаций, ассигнований из бюджета на содержание вузов (поскольку государство не поручает осуществлять НИОКР за счет этих средств), средств внебюджетных фондов (поскольку они не подчиняются органам исполнительной власти) и иностранных источников. Доля средств бюджета во ВЗИР по централизованной тематике была определена путем уменьшения доли средств бюджета на долю во ВЗИР децентрализованной тематики, представленной в субсидиях на финансовое обеспечение выполнения госзадания в сфере науки. Доля средств секторов науки во ВЗИР по централизованной тематике была определена путем умножения суммарной доли их средств во ВЗИР на долю средств бюджета во ВЗИР по централизованной тематике, исходя из того, что часть получаемых секторами бюджетных средств по централизованной тематике тратится ими на внешние НИОКР, будучи представленной в их расходах в той же пропорции, что и в их финансировании.

Доля централизованной тематики в затратах на инновации определялась по той же схеме на основе данных, публикуемых НИУ ВШЭ. При этом, в связи с тем, что данные о структуре расходов бюджета отсутствуют, а в состав собственных средств организаций включены их расходы (секторов) на внешние закупки, в расчете использовались соответствующие пропорции, сложившиеся в сфере НИОКР, например доля централизованной тематики в средствах бюджета. 
тематики во ВЗИР можно рекомендовать соответствующую перестройку структурных элементов госзадания в сфере науки: сокращение доли проектов развития, привязка доли ресурсного обеспечения организации к доле централизованной тематики, превращение конкурса лучших исследователей в вариант конкурса проектов лабораторий. Для повышения доли централизованной тематики во ВЗИР и затратах на инновации можно рекомендовать переход органов государственного управления к разработке и утверждению ПИР госкомпаний.

Для того, чтобы государственное управление подконтрольными организациями, осуществляющими НИОКР и инновации, было эффективным, в качестве главного финансового показателя им должна устанавливаться не прибыль, а затраты на содержание, что означает их фактическое превращение в бюджетные организации. Подконтрольность государству производственной организации, главным финансовым показателем деятельности которой является прибыль, при прочих равных условиях, обусловливает ее незаинтересованность в максимизации долгосрочной прибыли и, наоборот, крайнюю заинтересованность в максимизации краткосрочной прибыли. Максимизации же краткосрочной прибыли затраты на НИОКР и инновации мешают, в связи с чем организации, подконтрольные государству (речь идет прежде всего о госкомпаниях), стремятся либо уйти от этих затрат, либо занимаются имитацией соответствующей деятельности, обналичивая затраты на нее и получая налоговые льготы за НИОКР и инновации. Именно в силу стремления госкомпаний к максимизации краткосрочной прибыли их затраты на НИОКР и инновации до 2011 г. находились на крайне низком уровне, а для его повышения за счет принятия и реализации ПИР - пришлось прибегнуть к принудительным мерам (см. выше). Коммерческие НИИ, подконтрольные государству, также не заинтересованы в максимизации долгосрочной прибыли, т.е. в долгосрочных связях с заказчиками, в связи с чем стремятся завышать цену на НИОКР, по возможности снижать качество выполненных работ, активно участвуют в коррупционных схемах и т.д.

Данные, приведенные в таблице 5, характеризуют доли бюджетных организаций во ВЗИР и затратах на инновации. Из таблицы 5 также видно, что доля бюджетных организации в затратах на инновации крайне низка, хотя и имеет небольшую тенденцию к росту. При этом данная доля была в несколько раз ниже доли в затратах на инновации собственности, контролируемой государством. Если в 2016 г. первая составила $12,9 \%$, то последняя - 80,0. Даже если все бюджетные организации считать контролируемыми государством, то их доля в затратах на инновации, осуществлявшихся контролируемыми государством организациями, составит всего 16,1\% $(12,9 / 80,0 * 100)$.

Долей бюджетных организаций во ВЗИР может быть увеличена, прежде всего, посредством национализации НИИ, принадлежащих госкорпорациям, с их передачей в собственность органов исполнительной власти (ФОИВ). Доля бюджетных организаций в затратах на инновации может быть увеличена, прежде всего, путем превращения в бюджетные организации госкомпаний, в том числе ГУПов. Это позволит заставить госкомпании работать в интересах общества, а

Таблица 5. Доли бюджетных организаций во ВЗИР и затратах на инновации в 2000-2017 гг.,\%

\begin{tabular}{|l|c|c|c|c|c|c|c|c|c|c|}
\hline Доля бюджетных организаций & 2000 & 2005 & 2010 & 2011 & 2012 & 2013 & 2014 & 2015 & 2016 & 2017 \\
\hline 1. Во ВЗИР & 28,7 & 31,1 & 38,2 & 37,5 & 40,1 & 38,0 & 38,9 & 39,4 & 40,0 & 38,5 \\
\hline 2. В затратах на инновации & н/д & н/д & н/д & 5,7 & 10,0 & 10,0 & 12,3 & 12,5 & 12,9 & н/д \\
\hline
\end{tabular}

Источник: составлено авторами.

Примечание - Доля бюджетных организаций во ВЗИР была определена на основе публикуемых НИУ ВШЭ и ранее определенных данных о долях во ВЗИР государственного сектора науки, государственного сектора высшего образования и сектора некоммерческих организаций, имея в виду, что только организации этих секторов являются бюджетными (коммерческими являются организации предпринимательского сектора науки и частного сектора высшего образования).

Доля бюджетных организаций в затратах на инновации была определена по данным о затратах на инновации в НиР и доле бюджетных организаций во ВЗИР, имея в виду, что бюджетные организации представлены только в инновациях в НИР (инновации в остальных видах экономической деятельности осуществляют коммерческие организации).

Из таблицы 5 видно, что рост доли бюджетных организаций во ВЗИР, происходивший с начала века, в 2010 г. сменился на ее стабилизацию приблизительно на уровне 40\%. При этом доля бюджетных организаций во ВЗИР была существенно ниже доли в них собственности, контролируемой государством. Так, если в 2017 г. первая составила - 38,5\%, то последняя -89,9\%. Таким образом, даже если все бюджетные организации считать контролируемыми государством, то доля государственных бюджетных организаций во ВЗИР, осуществлявшихся подконтрольными государству организациями, составила только $42,8 \%$ $\left(38,5 / 89,9^{*} 100\right)$. 
не самих себя.

Очевидно, что адекватное управление государством подконтрольными ему организациями, осуществляющими НИОКР и инновациями, невозможно без назначения руководителей этих организаций на должности.

К сожалению, в последние годы существования СССР, на фоне общей волны демократизации управления в виде выборов руководителей предприятий их трудовыми коллективами, в нашей стране была введена выборность руководителей НИИ [11] и ректоров вузов [12, с. 106]. Выборность руководителей НИИ и ректоров вузов в целом сохранилась до наших дней в госсекторах науки и высшего образования, организации которых подконтрольны государству, хотя в последнее десятилетие сформировалась система изъятий из соответствующего правила. Выборность ректоров вузов была отменена для ректоров МГУ им. М.В. Ломоносова и СанктПетербургского государственного университета, назначаемых на должности Президентом РФ, ректоров федеральных университетов, назначаемых на должности Правительством РФ [13]. Выборность руководителей НИИ отменена для руководителей государственных научных центров, например для руководителя Национального исследовательского центра «Курчатовский институт», назначаемого на должность Правительством РФ [14].

В предпринимательском секторе, контролируемом государством, назначаемость руководителей организаций государством действует только в отношении руководителей организаций, капитал которых находится в 100-процентной и прямой собственности государства, а именно в отношении руководителей ГУПов, акционерных обществ со 100\% акций в собственности государства и госкорпораций. Так, генеральный директор ФГУП «Почта России» был назначен на должность приказом Министра связи и массовых коммуникаций РФ [15], генеральный директор ОАО «РЖД» со 100\% акций в собственности государства - распоряжением Правительства РФ [16], руководитель корпорации «Ростехнологии» - указом Президента РФ [17]. Руководители же других контролируемых государством организации предпринимательского сектора государством не назначаются, например Председатель Правления ПАО «Газпром» был избиран на должность Советом директоров общества [18].

В таблице 6 представлены данные о долях назначаемости государством руководителей организаций во ВЗИР и затратах на инновации, на основе которых может быть оценена степень назначаемости государством руководителей организаций, осуществляющих НИОКР и инновации, контролируемых государством.

Из таблицы 6 видно, что доля назначаемости руководителей во ВЗИР постоянно снижается, основной причиной чего является ликвидация производственных ГУПов. При этом доля назначаемости во ВЗИР существенно ниже, чем доля в них собственности, контролируемой государством. Если в 2017 г. первая составляла 28,4\%, то вторая - 89,9\%. Это значит, что только 31,6\% $(28,4 / 89,9 * 100)$ ВЗИР, осуществленных контролируемыми государством организациями, были осуществлены организациями, руководство которых назначается государством.

Таблица 6. Доля назначаемости государством руководителей организаций во ВЗИР и затратах на инновации в 2011-2017 гг.,\%

\begin{tabular}{|l|c|c|c|c|c|c|c|}
\hline Доля назначаемости руководителей организаций & 2011 & 2012 & 2013 & 2014 & 2015 & 2016 & 2017 \\
\hline 1. Во ВЗИР & 43,9 & 39,2 & 40,4 & 40,3 & 34,0 & 31,5 & 28,4 \\
\hline 2. В затратах на инновации & н/д & 16,3 & 16,1 & 18,4 & 17,1 & 12,3 & н/д \\
\hline
\end{tabular}

Источник: составлено авторами.

Примечание - Доля назначаемости государством руководителей организаций во ВЗИР была определена на основе данных о долях в этих затратах государственной формы собственности и собственности госкорпораций, публикуемых НИУ ВШЭ, и долях в них избираемости руководителей организаций госсекторов науки и высшего образования (руководители организаций частного сектора высшего образования и сектора некоммерческих организаций государством не назначаются). Последние доли, подлежащие вычету из первых, были определены по данным о долях данных секторов во ВЗИР, публикуемым НИУ ВШЭ и рассчитанным ранее соответственно, и данным о численности их организаций, в том числе организаций, руководители которых назначаются государством, и их относительных размерах этих организаций. Доля назначаемости государством руководителей организаций в затратах на инновации была определена на основе данных о долях госсобственности и собственности госкорпораций в затратах на инновации, публикуемым НИУ ВШЭ, и долях в данных затратах инноваций в НИР, приходящихся на госсекторы науки и высшего образования с избираемым руководством организации. Последние доли, подлежащие вычитанию из первых, были определены по данным о затратах на инновации и объемах инноваций в НИР, приходящиеся на госсекторы науки и высшего образования с избираемым руководством организаций, устанавливаемых по долям этих секторов во ВЗИР. 
Из таблицы 6 также видно, что доля назначаемости руководителей в затратах на инновации постоянно снижается, что объясняется, прежде всего, тем, что все большая доля инноваций, осуществляемых контролируемыми государством организациями, осуществляется госкомпаниями, капиталом которых государство владеет частично или косвенно. При этом доля назначаемости руководителей государством в затратах на инновации существенно ниже, чем доля в них собственности, контролируемой государством. Если в 2016 г. первая составляла 12,3\%, то вторая $-80,0 \%$. Это значит, что только $15,4 \%$ $(12,3 / 80,0 * 100)$ затрат на инновации, осуществленных организациями, контролируемыми государством, были осуществлены организациями, руководство которых назначается государством.

Таким образом, российское государство в значительной мере не использует возможности по усилению управляемости с его стороны подконтрольных ему организаций, осуществляющих НИОКР и инновации, в виде назначаемости их руководителей.

Увеличить долю назначаемости руководителей во ВЗИР, осуществляемых подконтрольными государству организациями, позволит отмена выборности руководителей НИИ госсектора и национализация части НИИ предпринимательского сектора науки. Увеличить таковую в инновациях, осуществляемых контролируемыми государством организациями, позволит национализация ряда госкомпаний с частичным или непрямым владением их акциями (капиталом) государством, либо внесение изменений в законодательство об акционерных обществах, которые позволили бы государству назначать их руководителей в соответствующих случаях.

Таким образом, российское государство, поставив под свой контроль подавляющую долю собственности в стране, занятую в НИОКР и инновациях, а также источников их финансирования, уделило абсолютно недостаточное налаживанию системы их эффективного использования. Субъекты управления многих подконтрольных государству организаций сектора НИОКР и инноваций не подчинены властной вертикали, недостаточно участие государства в утверждении тематики НИОКР и инноваций, оплачиваемых из источников, контролируемых государством, в качестве главного финансового показателя подконтрольных организаций фигурирует прибыль, не заинтересовывающая их в осуществлении ВЗИР и затрат на инновации, государство не назначает основную массу руководителей подконтрольных организаций. Возможно поэтому, несмотря на все усилия, российскому государству так и не удается вывести сектор НИОКР и инноваций из депрессивного состояния.

Примененный здесь инструментарий исследования (изучение количественных соотношений между альтернативными способами выполнения социальных функций, которые условно могут быть разделены на «государственные» и «частные») может быть использован в рамках анализа институциональной среды сектора знаний на основе X-Y-теории С.Г. Кирдиной [19], требующей обеспечения соотношения между государственными (или Х-) и частными (или Y-) способами исполнения соответствующих функций в странах «восточного» типа, к которым относится и Россия, в пропорции 67,5 к 32,5. В этом случае оценивается соответствие рассмотренных в настоящей статье долей «государственного» исполнения соответствующих функций (закрепление благ, обмен, устройство и форма управления, критерий эффективности, замещение должностей) X-норме, равной 67,5\%. На основе этого анализа российскому государству может быть рекомендовано существенное сокращение долей собственности, контролируемой государством, во ВЗИР и затратах на инновации, а также долей в них источников их финансирования, контролируемых государством, которые, как видно из таблиц 1 и 2, значительно превышают X-норму 67,5\%, путем приватизация части НИИ госкомпаний, увеличения доли в затратах на инновации предпринимательского сектора, не контролируемого государством, увеличение его доли этого сектора в финансировании НИОКР. Что касается рекомендаций, вытекающих из оценки соответствия Х-норме рассмотренных в настоящей статье долей государственного исполнения других функций, то они аналогичны сформулированным на основе сравнения этих долей с долями во ВЗИР и затратах на инновации собственности, контролируемой государством, и источников их финансирования, контролируемых государством. 


\section{Библиографический список}

1. Программы инновационного развития компаний с государственным участием: Промежуточные итоги и приоритеты / М.А. Гершман, Т.С. Зинина, М.А. Романов и др.; науч. ред. Л. М. Гохберг, А.Н. Клепач, П.Б. Рудник и др.; НИУ ВШЭ.- М.: НИУ ВШЭ, 2015. 128 с.

2. РЖД. Документы / Распоряжение Правительства РФ от 25.02.2004 № 265-р «Об утверждении Положения о совете директоров открытого акционерного общества «Российские железные дороги», Положения о правлении открытого акционерного общества «Российские железные дороги», Положения о ревизионной комиссии открытого акционерного общества «Российские железные дороги» URL: http://doc.rzd.ru/doc/ public/ru\%3FSTRUCTURE_ID\%3D704\%26layer_id\%3D5104\%26id\%3D3970\#4975.

3. Росатом. Органы управления. URL: https://rosatom.ru/about/management/.

4. Дежина, И.Г. Механизмы государственного финансирования науки в России.- М.: ИЭПП, 2006.130 с.

5. Трубников Г.В. Эффективная модель государственного задания в сфере науки. URL: https://www.cbias.ru/ wp-content/uploads/2017/03/2017_03_03_03_TrubnikovGV.pdf.

6. Индикаторы инновационной деятельности: 2018: Стат. сборник / Н. В. Городникова, Л. М. Гохберг, К.А. Дитковский и др.; НИУ ВШЭ.- М.: НИУ ВШЭ, 2018. 344 с. С. 195-198.

7. Статистика науки и образования. Выпуск 6. Затраты и источники финансирования научных исследований и разработок: Инф.-стат. мат.-М.: ФГБНУ НИИ РИНКЦЭ, 2018. 200 с. С. 112.

8. Программа инновационного развития ФГУП «ГКНПЦ им. М.В. Хруничева» на 2011-2015 годы. URL: www. khrunichev.ru/download/pasport_khr.pdf.

9. ПАСПОРТ Программы инновационного развития Государственной корпорации «Ростехнологии» на период 2011-2020 годов. URL: https://rostec.ru/content/files/reports/PasportPirRostec.pdf.

10. Системный оператор подвел итоги реализации программы инновационного развития в 2016 году URL: https://minenergo.gov.ru/en/node/8250.

11. Зверев Г.М. Памяти Александра Аполлоновича Казакова. URL: https://www.polyus.info/company/books/niipolyus-50-let/chapter06/.

12. Овсянников А.А. Система образования в России и образование России // Мир России. 1999. № 3. С. $73-132$.

13. Федеральный закон «О высшем и послевузовском профессиональном образовании» от 22.08.1996 № 125 Ф3 (последняя редакция). URL: http://www.consultant.ru/document/cons_doc_LAW_11446/.

14. Федеральный закон от 27 июля 2010 г. № 220-ФЗ «О национальном исследовательском центре «Курчатовский институт». URL: https://www.garant.ru/products/ipo/prime/doc/98885/.

15. ПОЧТА РОССИИ. Генеральный директор. URL: https://www.pochta.ru/director.

16. Распоряжение Правительства РФ от 17 ноября 2017 г. № 2546-p «О назначении Белозерова Олега Валентиновича генеральным директором-председателем правления OAO «Российские железные дороги». URL: https://base.garant.ru/71813004/.

17. Сергей Чемезов назначен главой «Ростехнологий». URL: https:/www.kommersant.ru/doc/829632.

18. Алексей Миллер избран Председателем Правления ПАО «Газпром» на новый пятилетний cpoк. URL: http:// www.gazprom.ru/press/news/2016/february/article266921/.

19. Кирдина, С.Г. Институциональные матрицы и развитие России: введение в Х-Ү-теорию.- СПб.: НесторИстория, 2014. 468 с. 